\title{
Factors Associated with Acute Malnutrition among Children Admitted to a Diarrhoea Treatment Facility in Bangladesh
}

\author{
Connor Fuchs, ${ }^{1}$ Tania Sultana, ${ }^{2}$ Tahmeed Ahmed, ${ }^{2}$ and M. Iqbal Hossain ${ }^{2}$ \\ ${ }^{1}$ University of Arkansas, Fayetteville, AR, USA \\ ${ }^{2}$ Centre for Nutrition and Food Security, and Nutrition Unit, Dhaka Hospital, icddr,b, Mohakhali, Dhaka 1212, Bangladesh \\ Correspondence should be addressed to M. Iqbal Hossain; ihossain@icddrb.org
}

Received 10 November 2013; Accepted 4 February 2014; Published 11 March 2014

Academic Editor: Samuel Menahem

Copyright (c) 2014 Connor Fuchs et al. This is an open access article distributed under the Creative Commons Attribution License, which permits unrestricted use, distribution, and reproduction in any medium, provided the original work is properly cited.

\begin{abstract}
To assess the risk factors for acute malnutrition (weight-for-height $z$-score (WHZ) $<-2$ ), a case-control study was conducted during June-September 2012 in 449 children aged 6-59 months (178 with WHZ $<-2$ and 271 comparing children with WHZ $\geq$ -2 and no edema) admitted to the Dhaka Hospital of icddr,b in Bangladesh. The overall mean \pm SD age was $12.0 \pm 7.6$ months, $38.5 \%$ (no difference between case and controls). The mean \pm SD WHZ of cases and controls was $-3.24 \pm 1.01$ versus $-0.74 \pm 0.95$ $(P<0.001)$, respectively. Logistic regression analysis revealed that children with acute malnutrition were more likely than controls to be older (age $>1$ year) (adjusted OR (AOR): 3.1, $P=0.004$ ); have an undernourished mother (body mass index < 18.5), (AOR: $2.8, P=0.017$ ); have a father with no or a low-paying job (AOR: 5.8, $P<0.001$ ); come from a family having a monthly income of $<10,000$ taka, (1 US\$ = 80 taka) (AOR: 2.9, $P=0.008$ ); and often have stopped predominant breastfeeding before 4 months of age (AOR: 2.7, $P=0.013$ ). Improved understanding of these characteristics enables the design and targeting of preventive-intervention programs of childhood acute malnutrition.
\end{abstract}

\section{Introduction}

One of every five children aged less than 5 years in lowincome, developing countries is malnourished. Globally, undernutrition is associated with more than one-third of all deaths in this age group [1]. Acute malnutrition defined by weight-for-height $z$-score (WHZ) $<-2$ (i.e., wasting) in young children continues to be a major health problem in low-income countries, particularly Bangladesh. Despite recent advances in prevention and management of childhood malnutrition in Bangladesh, $16 \%$ of children under 5 years of age are acutely malnourished (WHZ < -2) [2]. UNICEF describes malnutrition in Bangladesh as a "silent emergency" [3]. Childhood malnutrition places a heavy burden on many families in Bangladesh and other developing countries. It not only directly increases mortality but also imposes significant national health and development costs due to associated morbidities, including impaired cognitive ability and indirect deaths.
It is well documented that poverty and malnutrition, regardless of location, are highly intertwined. Although risk factors for malnutrition have been identified, individual factors potentially change in specific areas over time and a current characterisation of risk factors provides the basis for preventative intervention programmes.

\section{Methods}

The study was conducted in the Dhaka Hospital of the International Centre for Diarrhoeal Disease Research (icddr,b) situated in Dhaka, Bangladesh, a metropolitan area $(1,500 \mathrm{sq} \mathrm{km})$ with a total population of $\sim 15$ million. Each year, the Dhaka Hospital provides care and treatment for over 120,000 patients with diarrhoea, with or without other associated health problems. The hospital also conducts research on enteric and other common infectious diseases as well as undernutrition and provides training on case 
management of diarrheal diseases, management of malnutrition, and research methodology. Under-five children constitute about $60 \%$ of the total patient population and most $(\sim 60 \%)$ are from poor socioeconomic communities in urban and periurban areas of Dhaka.

A nonmatched case-control study design was used to assess and identify potential risk factors associated with acute malnutrition/wasting among 6-59-month-old children. Children in this age group without any congenital anomaly or other chronic conditions causally associated with malnutrition (e.g., heart disease), who were admitted to the Dhaka Hospital of icddr,b from June to September 2012, were enrolled. Using the contemporary growth standards of the World Health Organization (2006) and ANTHRO software [4], weight-for-height $z$-score (WHZ), weight-for-age $z$ score (WAZ), height-for-age $z$-score (HAZ), and body mass index-for-age $z$-score (BMI-AZ) of all studied children were calculated. Children with moderate or severe wasting (WHZ $<-2$ ) but without bilateral pedal edema were considered cases. Children with a WHZ $\geq-2$ and without bilateral pedal edema were enrolled as control children. Verbal consent from the attending guardian, usually the mother of the child, was obtained.

2.1. Data Collection. One of the investigators and/or a research assistant interviewed the mother/caregiver using a pretested, structured questionnaire. Data recorded from the interviews included age and sex of child, birth order, number of total and under-five siblings, feeding and immunisation history, type of house hold latrine, marital status of mother, monthly family income, and parental age, education, and occupation. Children's nude weight using a frequently standardised digital scale with $10 \mathrm{~g}$ precision (Seca, model 345, Hamburg, Germany) and recumbent length to the nearest mm using a calibrated, locally constructed length board were obtained. Mother's (if present) weight and height were measured using standard procedures [5]. The investigator(s) supervised the interview process and anthropometry and reviewed the data forms daily.

2.2. Data Analyses. Data were entered using SPSS software for Windows (version 11.5) (SPSS Inc., Chicago, IL, USA). For normally distributed continuous variables, means were compared using unpaired $t$-tests. For continuous variables not normally distributed, the Mann-Whitney $U$ test was performed. Differences in proportions were compared by the chi-square test or Fisher's exact test if the expected number in any cell was $\leq 5$. A probability of less than 0.05 was considered statistically significant. The strength of association of selected associated/risk factors for acute malnutrition was determined by estimating odds ratios (ORs) and their 95\% confidence intervals (CIs). All independent variables, for example, birth order, number of siblings, socioeconomic status, parental characteristics, child feeding, and immunisation history, were analysed initially in univariate models and the attributes that were significantly associated with wasting (dependent variable) and biologically plausible were included in logistic regression models.

\section{Results}

A total of 449 children were enrolled, of whom 178 were cases (wasted children) and 271 were controls. Their overall mean \pm SD age was $12.0 \pm 7.6$ months (cases were on an average 2 months older), and 38.5\% were female without any group difference between case and control children. The mean \pm SD WHZ and BMIAZ of case and control children were $-3.24 \pm 1.01$ versus $-0.74 \pm 0.95$ and $-3.21 \pm$ 1.04 versus $-0.77 \pm 0.96$, respectively $(P<0.001)$. As dictated by the study design, the cases had significantly lower anthropometric values than the control children (Table 1). Cases had a shorter period than controls of exclusive or predominant breastfeeding. Maternal nutritional status, family income, and the fathers' educational levels were worse in the malnourished children (cases). Cases had worse immunization status (Bacillus Calmette-Guérin (BCG) and measles vaccine), breastfeeding duration, and parental and other socioeconomic characteristics than control children (Table 2). Logistic regression analysis revealed that children with acute malnutrition were more likely than control to be older (age $>1$ year) (adjusted OR (AOR): 3.1, $P=0.004$ ), have an undernourished mother (body mass index (BMI) $<$ 18.5), (AOR: $2.8, P=0.017$ ), have a father with no or a low-paying job (AOR: 5.8, $P<0.001$ ), come from a family having a monthly income of less than 10,000 taka, (1 US\$ = 80 taka) (AOR: 2.9, $P=0.008$ ), and have shorter period of predominant breastfeeding (AOR: 2.7, $P=0.013$ ) (Table 3).

\section{Discussion}

The aim of this study was to identify risk factors associated with acute malnutrition (WHZ $<-2$, which includes both moderate and severe wasting) in our population of 659-month-old children. Our study shows that the major associated/risk factors for acute malnutrition among these children were older age of the child, undernourished mother, jobless father or father with a low-paying job, low total family income, and poorer breastfeeding practices. Some of these factors may operate in synergy to increase the risk of acute malnutrition.

Older age as a risk/associated factor for acute malnutrition of children in our study might reflect a selection bias. However, Jeyaseelan and Lakshman from Tamil Nadu, India [6], and Kikafunda et al. from Uganda [7] also observed older age of a child to be significantly associated with malnutrition. Proper nutrition and child care are essential to begin in early childhood to prevent malnutrition and ensure maximum potential for normal psychomotor development as children grow older.

Similar to other studies from Bangladesh [8-11] and Africa [12], the current study observed maternal malnutrition (BMI less than 18.5) as an independent risk factor for children's wasting/acute malnutrition. Undernourished mothers often deliver low-birth-weight (LBW) infants [13], which is an attributable risk factor for increased childhood malnutrition, morbidity, and mortality. The last nationwide LBW survey in Bangladesh showed a high prevalence of $36 \%$. The capacity to adequately breastfeed may also be compromised [14-16] 
TABLE 1: Characteristics (continuous variables) of the cases (wasted) and controls (nonwasted) children.

\begin{tabular}{|c|c|c|c|}
\hline Variable & $\begin{array}{c}\text { Case } \\
N=178\end{array}$ & $\begin{array}{l}\text { Control } \\
N=271\end{array}$ & $P$ value \\
\hline Child's age (months) & $13.4 \pm 4.0$ & $11.2 \pm 6.6$ & 0.004 \\
\hline Weight-for-length $z$-score ${ }^{\mathrm{a}}$ & $-3.24 \pm 1.01$ & $-0.74 \pm 0.95$ & $<0.001$ \\
\hline Weight-for-age $z$-score ${ }^{\mathrm{a}}$ & $-3.46 \pm 1.34$ & $-1.08 \pm 1.19$ & $<0.001$ \\
\hline Length-for-age $z$-score ${ }^{\mathrm{a}}$ & $-2.16 \pm 1.84$ & $-0.88 \pm 1.45$ & $<0.001$ \\
\hline BMI-for-age $z$-score ${ }^{\mathrm{a}}$ & $-3.21 \pm 1.04$ & $-0.77 \pm 0.96$ & $<0.001$ \\
\hline Total number of children in the family & $1.8 \pm 1.0$ & $1.7 \pm 0.9$ & 0.270 \\
\hline Exclusive/predominant breastfeeding (month) & $4.0 \pm 2.6$ & $4.4 \pm 2.4$ & 0.042 \\
\hline Birth order & $1.8 \pm 1.0$ & $1.7 \pm 0.8$ & 0.365 \\
\hline Mother's age (years) & $23.7 \pm 5.2$ & $23.9 \pm 4.7$ & 0.737 \\
\hline Mother's weight (kg) & $45.0 \pm 7.8$ & $50.4 \pm 10.2$ & $<0.001$ \\
\hline Mother's height (meter) & $1.49 \pm 0.05$ & $1.50 \pm 0.06$ & $<0.001$ \\
\hline Mother's body mass index $\left(\mathrm{kg} / \mathrm{M}^{2}\right)$ & $20.4 \pm 3.4$ & $22.3 \pm 4.0$ & $<0.001$ \\
\hline Mother's education (years) & $5.0 \pm 4.2$ & $7.5 \pm 3.9$ & $<0.001$ \\
\hline Father's age (years) & $30.8 \pm 6.8$ & $31.5 \pm 5.7$ & 0.249 \\
\hline Father's education (years) & $5.8 \pm 4.6$ & $8.3 \pm 4.3$ & $<0.001$ \\
\hline Total family income per month (taka ${ }^{\mathrm{b}}$ ) & $10128 \pm 6647$ & $16095 \pm 16489$ & $<0.001$ \\
\hline
\end{tabular}

All data are expressed as mean \pm SD. ${ }^{a}$ In relation to the WHO 2006 standard [4]; ${ }^{b}$ taka (Bangladeshi currency: 1 UD $\$=80$ taka, average rate during the study period).

TABLE 2: Characteristics (attributes) of the cases (wasted) and controls (nonwasted) children.

\begin{tabular}{|c|c|c|c|}
\hline Variable & $\begin{array}{c}\text { Case } \\
N=178\end{array}$ & $\begin{array}{l}\text { Control } \\
N=271\end{array}$ & $P$ value \\
\hline Child's age > 1 year: $n(\%)$ & $67(37.6)$ & $62(22.9)$ & 0.001 \\
\hline Girls: $n(\%)$ & $74(41.6)$ & $99(36.5)$ & 0.283 \\
\hline Did not receive BCG: $n(\%)$ & $5(2.8)$ & $1(0.4)$ & 0.038 \\
\hline $\begin{array}{l}\text { Did not receive pentavalent/polio vaccine } \\
\text { (or received less than age appropriate doses): } n(\%)\end{array}$ & $16(9.0)$ & $23(8.5)$ & 0.984 \\
\hline $\begin{array}{l}\text { Did not receive measles vaccine (among }>9 \text { months old; } \\
n=109 \text { cases and } 142 \text { controls): } n(\%)\end{array}$ & $31(28.4)$ & $26(18.3)$ & 0.041 \\
\hline Predominant breastfeeding stopped before 4 months: $n(\%)$ & $76(42.7)$ & $85(31.4)$ & 0.010 \\
\hline Teenaged mother $(<20$ years): $n(\%)$ & $23(13.4)$ & $21(7.9)$ & 0.045 \\
\hline Shorter mother (height $<1.5$ meters): $n(\%)$ & $86(54.4)$ & $110(44.5)$ & 0.033 \\
\hline Undernourished mother $(\mathrm{BMI}<18.5): n(\%)$ & $52(32.5)$ & $37(14.9)$ & $<0.001$ \\
\hline Illiterate or less educated ( $<5$ years' schooling) mother: $n(\%)$ & $101(56.7)$ & $88(32.5)$ & $<0.001$ \\
\hline Mother working outside of the home: $n(\%)$ & $15(8.4)$ & $12(4.4)$ & 0.063 \\
\hline Divorced/widowed mother: $n(\%)$ & $16(9.0)$ & $3(1.1)$ & $<0.001$ \\
\hline Younger father (age $<25$ years): $n(\%)$ & $44(25.4)$ & $37(14.3)$ & 0.003 \\
\hline Illiterate or less educated ( $<5$ years' schooling) father: $n(\%)$ & $92(52.6)$ & $72(27.0)$ & $<0.001$ \\
\hline $\begin{array}{l}\text { Father with low-paid job: } n(\%) \\
\text { (e.g., rickshaw puller or day labourer): } n(\%)\end{array}$ & $149(83.7)$ & $139(51.3)$ & $<0.001$ \\
\hline Monthly income $<10000$ taka $^{\mathrm{a}}: n(\%)$ & $121(70.3)$ & $136(51.5)$ & $<0.001$ \\
\hline Using unsanitary latrine: $n(\%)$ & $10(5.6)$ & $3(1.1)$ & 0.006 \\
\hline Child worn any thread or amulet: $n(\%)$ & $94(53.1)$ & $157(57.9)$ & 0.331 \\
\hline Child worn kajal ${ }^{\mathrm{b}}$ at the side of fore head: $n(\%)$ & $139(78.1)$ & $219(80.8)$ & 0.549 \\
\hline
\end{tabular}

All data are expressed as number (\%). ${ }^{a}$ Taka (Bangladeshi currency: 1 UD\$ $=80$ taka, average rate during the study period); ${ }^{b}$ a black mark/line used over eyelash by females and side of forehead in some children in Indo-Pak subcontinent. 
TABLE 3: Factors associated with acute malnutrition (wasting): results of logistic regression model.

\begin{tabular}{|c|c|c|c|c|}
\hline \multirow{2}{*}{ Attribute } & \multirow{2}{*}{ Adjusted odds ratio } & \multicolumn{2}{|c|}{$95 \% \mathrm{CI}$ of adjusted OR } & \multirow{2}{*}{$P$ value } \\
\hline & & Lower & Upper & \\
\hline Child's age $>1$ year & 3.144 & 1.431 & 6.904 & 0.004 \\
\hline $\begin{array}{l}\text { Did not receive measles vaccine (among }>9 \text { months old; } \\
n=109 \text { cases and } 142 \text { controls) }\end{array}$ & 2.492 & 0.973 & 6.378 & 0.057 \\
\hline Predominant breastfeeding stopped before 4 months & 2.669 & 1.229 & 5.796 & 0.013 \\
\hline Teenaged mother $(<20$ years $)$ & 1.758 & 0.451 & 6.847 & 0.416 \\
\hline Shorter mother (height $<1.5$ meters) & 1.399 & 0.686 & 2.851 & 0.355 \\
\hline Undernourished mother $(\mathrm{BMI}<18.5)$ & 2.803 & 1.203 & 6.532 & 0.017 \\
\hline Illiterate or less educated ( $<5$ years' schooling) mother & 1.676 & 0.754 & 3.728 & 0.205 \\
\hline Younger father (age $<25$ years $)$ & 1.614 & 0.682 & 3.815 & 0.276 \\
\hline Illiterate or less educated ( $<5$ years' schooling) father & 1.186 & 0.525 & 2.682 & 0.681 \\
\hline Father with low-paid job & 5.778 & 2.537 & 13.157 & $<0.001$ \\
\hline Monthly income $<10000$ taka $^{a}$ & 2.871 & 1.310 & 6.291 & 0.008 \\
\hline Using unsanitary latrine & 1.505 & 0.078 & 29.173 & 0.787 \\
\hline Constant & 0.016 & - & - & 0.001 \\
\hline
\end{tabular}

Taka (Bangladeshi currency: $1 \mathrm{UD} \$=80$ taka, average rate during the study period).

in maternal malnutrition and such mothers might have less energy to appropriately nurture their children.

The fathers of most (84\%) of the wasted children in our study were rickshaw pullers or day laborers. Likewise, a study from South India [17] also found that children of fathers who were day laborers were $\sim 3$ times more likely to be severely underweight. These occupations are among the lowest paid employment categories in Bangladesh. Moreover, they often result in erratic or insecure incomes, at times yielding little or no earnings on a particular day. Income insecurity leads to food insecurity forcing family members to consume poor food quality and/or amount. Low family income as a possible risk factor of acute malnutrition, as found in this study, was also reported by Ahmed et al. [8] in wasted children under 2 years old, by Nahar et al. [18] in severely underweight under-5 children in Bangladesh, and by Jeyaseelan and Lakshman [6] in undernourished children in Tamil Nadu, India.

Our finding of improper/inadequate breastfeeding as an associated factor with acute malnutrition is in accordance with the findings of several other studies $[10,19,20]$ from Bangladesh and elsewhere, in which early supplementation with infant formula or cow's milk, early introduction of semisolid complementary foods, and inadequate breastfeeding were important risk factors for malnutrition in children. During the critical period of early infancy, proper breastfeeding and complementary feeding practices play critical roles. The hygienic and nutritional risks associated with bottlefeeding and artificial milk are well known [21-23], and previous studies also found that breastfeeding had a significant and substantial impact on overall survival of undernourished children $[24,25]$. It is also possible that the association with a shorter duration of predominant breastfeeding could be an example of reverse causality, whereby children who were ill and undernourished stopped breastfeeding or were provided with other foods.
One of the possible limitations of the present study is that the same personnel who obtained the anthropometric measurements of the children and mothers also conducted the interviews, so interviewer biases could be there. However, most of the variables identified as risk/associated factors for acute malnutrition in our study were objective in type. The other limitation was the cross-sectional nature of the present study, which did not allow us to state the identified associated factors as definite causally related risk factors.

The children suffering from acute malnutrition often need supplementary food. In this regard it is worthwhile to mention that icddr,b has developed ready-to-use foods using locally available food ingredients. These foods can be used to prevent and to treat moderate wasting in children living in food-insecure communities. Moreover, the associated factors identified for acute malnutrition in this study can be incorporated into the design and targeting of preventive interventions. Factors such as breastfeeding practices are potentially modifiable. Interventions that motivate behaviours more consistent with recommended infant and young child feeding practices would be expected to have a positive impact. Certain factors and possible causes of acute malnutrition are complex and involve societal and broadbased preventive programs.

\section{Conflict of Interests}

None of the authors/investigators has any financial interests that might affect the results of this study.

\section{Authors' Contribution}

Each author has taken part in conception and design, analysis and interpretation of data, and drafting and/or revising the paper. 


\section{Acknowledgments}

This study was supported by icddr,b. This research/study was funded by core donors which provide unrestricted support to icddr,b for its operations and research. Current donors providing unrestricted support include Australian Agency for International Development (AusAID), Government of the People's Republic of Bangladesh, Canadian International Development Agency (CIDA), Swedish International Development Cooperation Agency (Sida), and the Department for International Development, UK (DFID). The authors gratefully acknowledge these donors for their support and commitment to icddr,b's research efforts. They sincerely appreciate Professor G. J. Fuchs, Department of Pediatric Gastroenterology and Nutrition, Arkansas Children's Hospital, USA, for his excellent review and input in this study. The study and its reporting are approved by the institutional review board of icddr,b without any ethical concern.

\section{References}

[1] R. E. Black, L. H. Allen, Z. A. Bhutta et al., "Maternal and child undernutrition: global and regional exposures and health consequences," The Lancet, vol. 371, no. 9608, pp. 243-260, 2008.

[2] National Institute of Population Research and Training (NIPORT), Maitra and Associates, and Macro International, "Bangladesh Demographic and Health Survey 2011," National Institute of Population Research and Training, Maitra and Associates, and Macro International, Dhaka, Bangladesh and Calverton, Md, USA, 2012.

[3] S. Crowe, “'A silent emergency' as Bangladesh's poor suffer from economic downturn," Newsline, Unicef information by country, 2009, http://www.unicef.org/infobycountry/ bangladesh_49247.html.

[4] WHO Multicentre Growth Reference Study Group, "WHO Child Growth Standards: Length/height-for-age, weight-forage, weight-for-length, weight-for-height and body mass indexfor-age: Methods and development," Geneva, Switzerland, World Health Organization, 2006, http://www.who.int/ childgrowth/standards/technical_report/en/index.html.

[5] WHO, "Physical status. The use and interpretation of anthropometry," Report of a WHO Expert Committee WHO Technical Report Series 854, World Health Organization, Geneva, Switzerland, 1995.

[6] L. Jeyaseelan and M. Lakshman, "Risk factors for malnutrition in south Indian children," Journal of Biosocial Science, vol. 29, no. 1, pp. 93-100, 1997.

[7] J. K. Kikafunda, A. F. Walker, D. Collett, and J. K. Tumwine, "Risk factors for early childhood malnutrition in Uganda," Pediatrics, vol. 102, no. 4, article E45, 1998.

[8] A. S. Ahmed, T. Ahmed, S. K. Roy, N. Alam, and M. I. Hossain, "Determinants of under nutrition in children under 2 years of age from rural Bangladesh," Indian Pediatrics, vol. 49, pp. 821824, 2012.

[9] M. I. Rayhan and M. S. H. Khan, "Factors causing malnutrition among under five children in Bangladesh," Pakistan Journal of Nutrition, vol. 5, no. 6, pp. 558-562, 2006.

[10] A. Rahman and S. Chowdhury, "Determinants of chronic malnutrition among preschool children in Bangladesh," Journal of Biosocial Science, vol. 39, no. 2, pp. 161-173, 2007.
[11] M. Aminul Islam, M. Mujibur Rahman, and D. Mahalanabis, "Maternal and socioeconomic factors and the risk of severe malnutrition in a child: a case-control study," European Journal of Clinical Nutrition, vol. 48, no. 6, pp. 416-424, 1994.

[12] F. Delpeuch, P. Traissac, Y. Martin-Prével, J. P. Massamba, and B. Maire, "Economic crisis and malnutrition: socioeconomic determinants of anthropometric status of preschool children and their mothers in an African urban area," Public Health Nutrition, vol. 3, no. 1, pp. 39-47, 2000.

[13] M. S. Kramer, "The epidemiology of adverse pregnancy outcomes: an overview," Journal of Nutrition, vol. 133, no. 5, pp. 1592S-1596S, 2003.

[14] T. S. Osteria, "Maternal nutrition, infant health, and subsequent fertility," Philippine Journal of Nutrition, vol. 35, no. 3, pp. 106111, 1982.

[15] K. H. Brown, N. A. Akhtar, A. D. Robertson, and M. G. Ahmed, "Lactational capacity of marginally nourished mothers: relationships between maternal nutritional status and quantity and proximate composition of milk," Pediatrics, vol. 78, no. 5, pp. 909-919, 1986.

[16] K. H. Brown, A. D. Robertson, and N. A. Akhtar, "Lactational capacity of marginally nourished mothers: infants' milk nutrient comsumption and patterns of growth," Pediatrics, vol. 78, no. 5, pp. 920-927, 1986.

[17] K. Saito, J. R. Korzenik, J. F. Jekel, and S. Bhattacharji, "A case-control study of maternal knowledge of malnutrition and health- care-seeking attitudes in rural South India," Yale Journal of Biology and Medicine, vol. 70, no. 2, pp. 149-160, 1997.

[18] B. Nahar, T. Ahmed, K. H. Brown, and M. I. Hossain, "Risk factors associated with severe underweight among young children reporting to a diarrhoea treatment facility in Bangladesh," Journal of Health, Population and Nutrition, vol. 28, no. 5, pp. 476-483, 2010.

[19] F. J. Henry, A. Briend, V. Fauveau, S. A. Huttly, M. Yunus, and J. Chakraborty, "Gender and age differentials in risk factors for childhood malnutrition in Bangladesh," Annals of Epidemiology, vol. 3, no. 4, pp. 382-386, 1993.

[20] F. J. Henry, A. Briend, V. Fauveau, S. R. A. Huttly, M. Yunus, and J. Chakraborty, "Risk factors for clinical marasmus: a casecontrol study of Bangladeshi children," International Journal of Epidemiology, vol. 22, no. 2, pp. 278-283, 1993.

[21] J. M. Jason, P. Nieburg, and J. S. Marks, "Mortality and infectious disease associated with infant-feeding practices in developing countries," Pediatrics, vol. 74, no. 4, pp. 702-727, 1984.

[22] K. H. Brown, R. E. Black, G. Lopez de Romana, and H. Creed de Kanashiro, "Infant-feeding practices and their relationship with diarrheal and other diseases in Huascar (Lima), Peru," Pediatrics, vol. 83, no. 1, pp. 31-40, 1989.

[23] B. M. Popkin, L. Adair, J. S. Akin, R. Black, J. Briscoe, and W. Flieger, "Breast-feeding and diarrheal morbidity," Pediatrics, vol. 86 , no. 6 , pp. $874-882,1990$.

[24] A. Briend, B. Wojtyniak, and M. G. M. Rowland, "Breast feeding, nutritional state, and child survival in rural Bangladesh," British Medical Journal, vol. 296, no. 6626, pp. 879-882, 1988.

[25] A. Briend and A. Bari, "Breastfeeding improves survival, but not nutritional status, of 12-35 months old children in rural Bangladesh," European Journal of Clinical Nutrition, vol. 43, no. 9, pp. 603-608, 1989. 


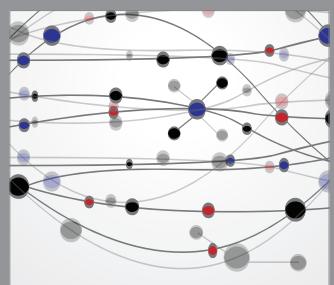

The Scientific World Journal
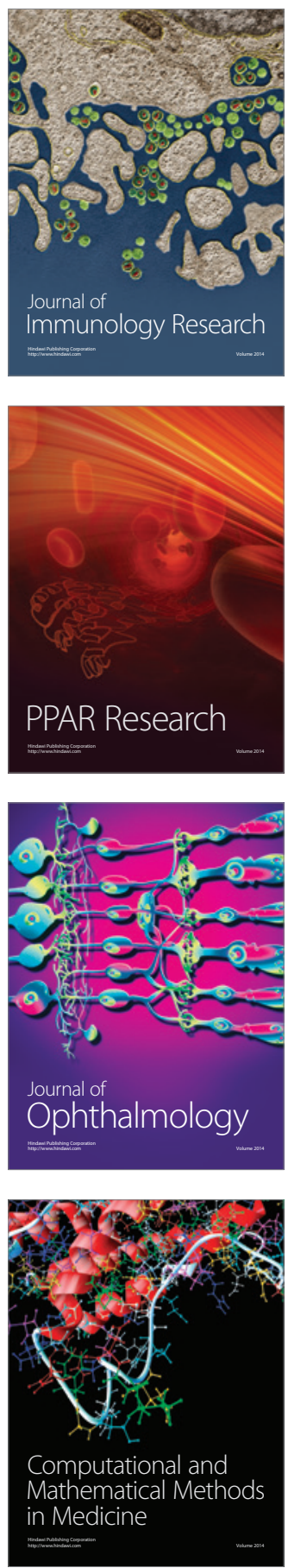

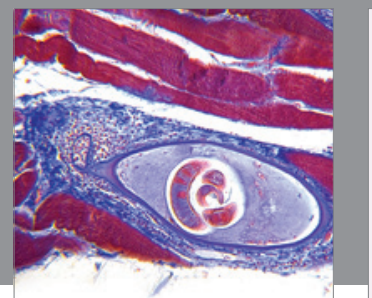

Gastroenterology

Research and Practice
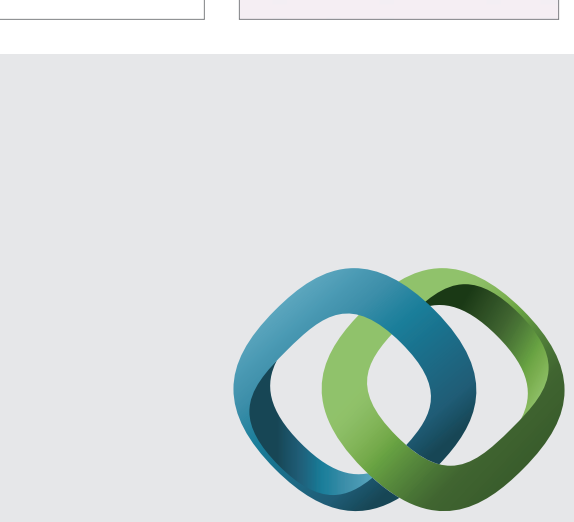

\section{Hindawi}

Submit your manuscripts at

http://www.hindawi.com
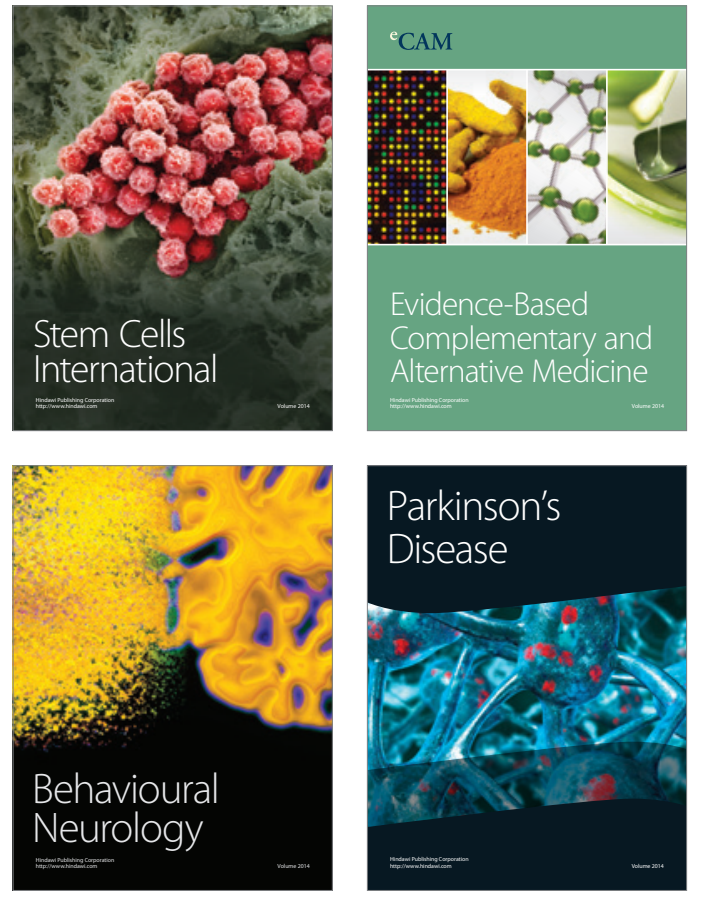
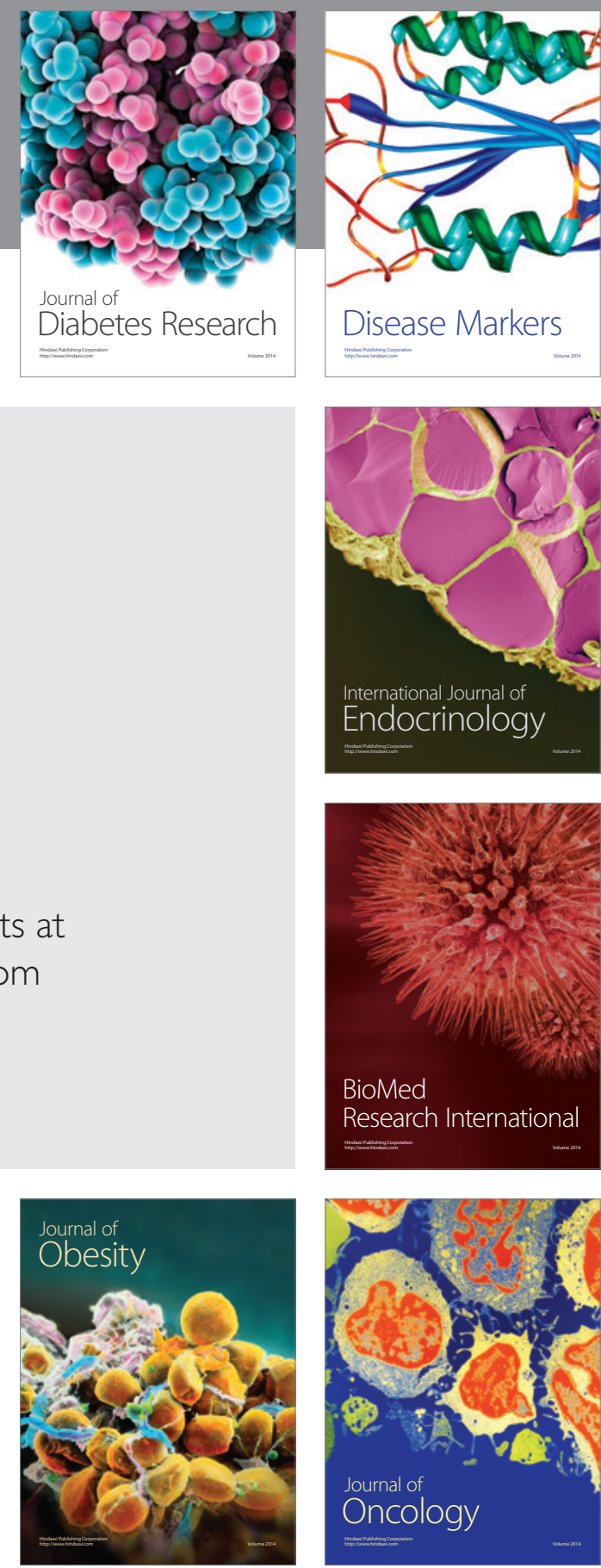

Disease Markers
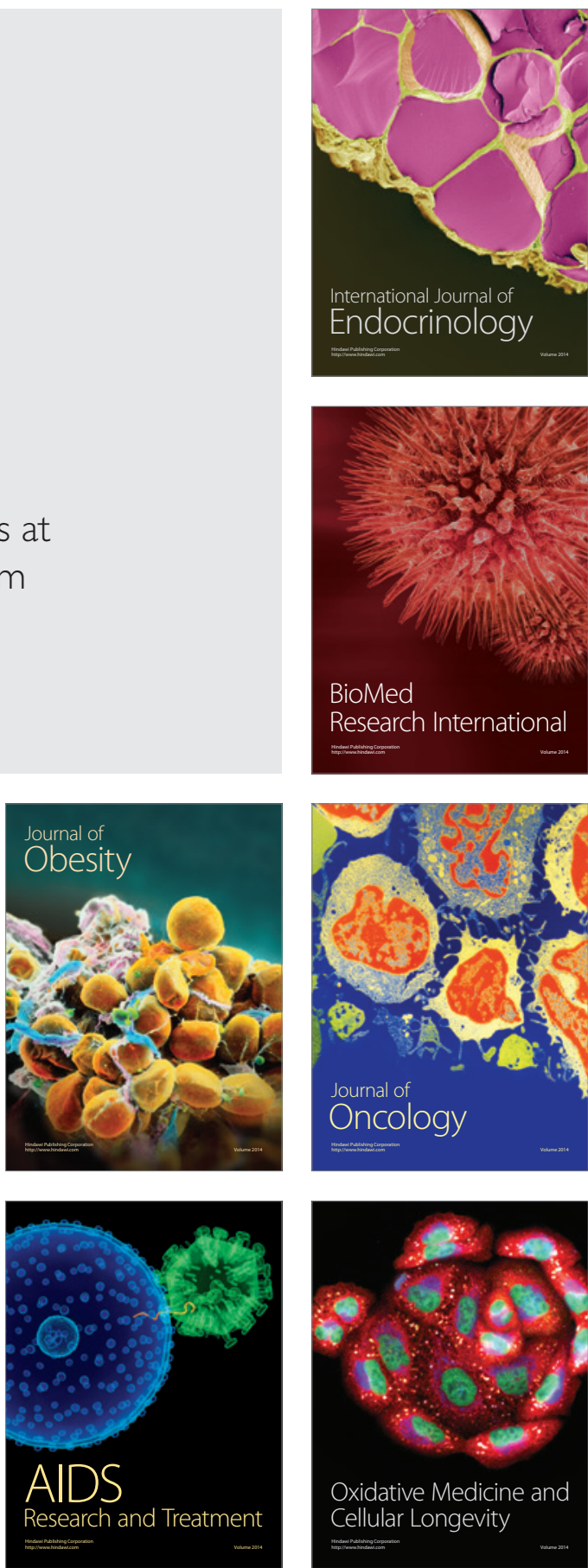